\title{
Feasibility study of high-precision trigonometric elevation replacing second-order level in tunnel penetration control survey
}

\author{
Zhang Hongfeng \\ Fifth Geological Engineering Survey Institute of Shanxi Province, Linfen, 041000, Shanxi
}

\begin{abstract}
Based on the principle of trigonometric elevation measurement and the law of error propagation, the trigonometric elevation formula is derived in this paper. The factors that cause the trigonometric measurement error are analyzed accurately. It is considered that the use of a high-precision total station for the trigonometric elevation measurement under opposite conditions can reach the second-order level measurement accuracy.
\end{abstract}

\section{Introduction}

In this paper, the trigonometric elevation measurement of the total station replacing the second-order leveling was studied. Conventional leveling has a short sight line, and it is very difficult to transmit second-order elevation in mountainous areas with large terrain differences and river crossings where measurement conditions are limited. With the advent of high-precision total stations, total stations are used to accurately measure distances and angles. Whether the trigonometric elevation survey can replace the second-order level survey has become an urgent problem for surveying and mapping staff. This article combines the principle and method of total station trigonometric elevation measurement to analyze the factors that cause its error.

\section{Principle and accuracy analysis of elevation measurement}

\subsection{Principle of one-way observation height difference}

To observe the height difference $\mathrm{hAB}$ at two points $\mathrm{AB}$, place the instrument at $A$, the instrument height is $i$, the reflection prism is at point $\mathrm{B}$, and the prism height is 1 , as shown in Figure 1.

Then $\mathrm{h}_{A B}=h^{\prime}+\mathrm{c}+i-l-r(1)$

Because the ratio of the distance between $\mathrm{AB}$ and the radius of the earth is small, it can be considered that $\angle$ $\mathrm{PNM}=90^{\circ}, \mathrm{h}^{\prime}=\mathrm{S} \sin \alpha \triangle$ in PNM (2)

Where $\mathrm{S}$ is the slope distance between $\mathrm{AB}$ and $\alpha$ is the vertical angle of the center of the collimating prism. $\mathrm{C}$ and $\mathrm{r}$ are the effects of earth curvature and atmospheric refraction, respectively [1].

$$
\mathrm{C}=\frac{S^{2}}{2 R} \operatorname{Cos}^{2} \alpha(3)
$$

$$
\mathrm{r}=\frac{S^{2}}{2 \mathrm{R}^{\prime}} \cos ^{2} \mathrm{a}(4)
$$

Where $\mathrm{R}$ is the radius of curvature of the earth, and $\mathrm{R}^{\prime}$ is the radius of curvature of the optical path curve ( $@$ (aQ),

Let $\mathrm{K}=\frac{R}{\mathrm{R}^{\prime}}$ be the atmospheric refractive index,

Then $\mathrm{r}=\frac{S^{2}}{2 \frac{R}{2 K}} \operatorname{CoS}^{2} \alpha=\frac{K S^{2}}{2 R} \operatorname{CoS}^{2} \alpha(5)$

Substituting (2), (3), and (5) into (1), then

$$
h_{A B}=\mathrm{S} \sin \alpha+\frac{1-k}{2 R} S^{2} \cos ^{2} a+i-l(6)
$$

Equation (6) is the basic formula for one-way observation of height difference.

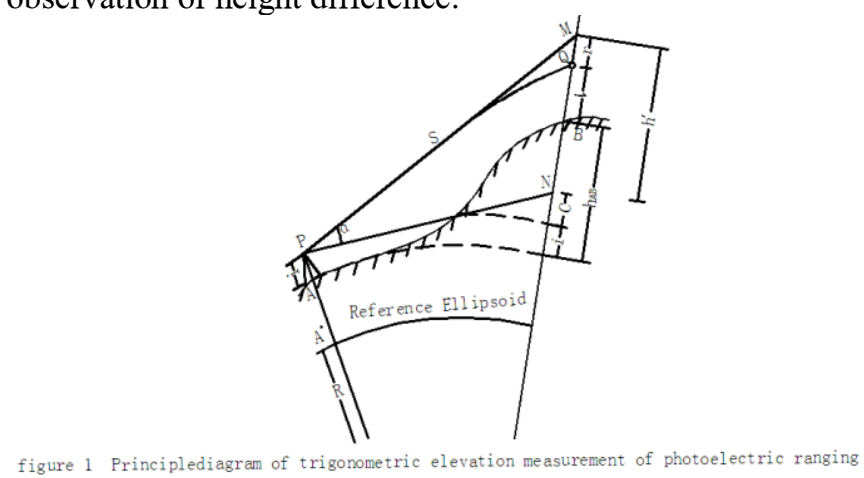

\subsection{Principle of opposite observation height difference}

The opposite observation is also called round-trip measurement, that is, the instrument is set at point $\mathrm{A}$, and the prism is set at point B when the test is performed, the instrument is set at point $\mathrm{B}$, and the prism is set at point A during the back test, then

$$
\begin{aligned}
& h_{A B}=S_{A B} \sin \alpha_{A B}+\frac{1-K_{A B}}{2 R} S_{A B}^{2} \cos ^{2} \alpha_{A B}+i_{A B}-l_{A B}(7) \\
& h_{B A}=S_{B A} \sin \alpha_{B A}+\frac{1-K_{B A}}{2 R} S_{B A}^{2} \cos ^{2} \alpha_{B A}+i_{B A}-l_{B A}(8) \\
& \text { Under the same observation conditions, } K_{A B} \approx K_{B A}, \\
& S_{B A} \cos \alpha_{B A} \approx S_{A B} \cos \alpha_{A B}
\end{aligned}
$$


Take the average of the round-trip height difference as the height difference between the two points of $\mathrm{AB}$, namely:

$$
\begin{gathered}
\overline{\mathrm{h}}=\frac{h_{A B}-h_{B A}}{2} \\
=\frac{1}{2}\left(S_{A B} \sin \alpha_{A B}-S_{B A} \sin \alpha_{B A}\right)+\frac{1}{2}\left(\mathrm{i}_{A B}-1_{A B}\right)-\frac{1}{2}\left(\mathrm{i}_{B A}-1_{B A}\right)^{(9)}
\end{gathered}
$$

This indicates that the use of the opposite observation method can effectively eliminate or reduce the influence of the spherical aberration on the trigonometric elevation measurement.

\subsection{Medium error of opposite trigonometric elevation measurement}

Differentiate the formula, and transform it into the medium error relationship equation, high $=\mathrm{i}-1$, because the instrument and observation conditions are the same, it is preferable that the errors in the round-trip measurement are equal to obtain the medium error formula of the opposite observation:

$m_{\bar{h}}=$

$\sqrt{\frac{1}{2}(\mathrm{~S} \cos \alpha)^{2} \times\left(\frac{m_{\alpha}}{\rho}\right)^{2}+\frac{1}{2}(\sin a)^{2} \times m_{s}^{2}+\frac{1}{2} m_{\mathrm{high}}{ }^{2}}(10)$

\section{Error analysis of the TS60 total station opposite observation height difference}

The TS60 total station has the following superior indicators: (1) with automatic sighting (ATR) function. (2) ATR angle measurement accuracy is 0.5 ". (3) Distance measurement accuracy is $0.6 \mathrm{~mm}+1 \mathrm{ppm}$.

The following uses the TS60 total station as an example to analyze the cause of the elevation error in the opposite observation. According to the formula, it can be

\begin{tabular}{|c|c|c|c|c|c|c|c|c|c|c|c|c|}
\hline \multirow{2}{*}{$\begin{array}{c}\text { Vertical } \\
\text { angle }\end{array}$} & \multirow{2}{*}{\multicolumn{2}{|c|}{ Error influence }} & \multicolumn{10}{|c|}{ Side length $(\mathrm{m})$} \\
\hline & & & 100 & 200 & 300 & 400 & 500 & 700 & 800 & 900 & 1000 & 1200 \\
\hline \multirow{4}{*}{$3^{\circ}$} & $\begin{array}{l}\mathrm{m}_{\alpha} \text { infl } \\
\text { uence }\end{array}$ & \multirow{3}{*}{$\mathrm{mm}^{2}$} & 0.019 & 0.075 & 0.169 & 0.300 & 0.469 & 0.919 & 1.200 & 1.519 & 1.875 & 2.700 \\
\hline & $\begin{array}{l}\mathrm{m}_{\mathrm{s}} \text { infl } \\
\text { uence }\end{array}$ & & 0.002 & 0.002 & 0.002 & 0.003 & 0.003 & 0.004 & 0.004 & 0.005 & 0.005 & 0.007 \\
\hline & $\begin{array}{l}\mathrm{m}_{\text {lighinfl }} \\
\text { uence }\end{array}$ & & 1.000 & 1.000 & 1.000 & 1.000 & 1.000 & 1.000 & 1.000 & 1.000 & 1.000 & 1.000 \\
\hline & $2 \mathrm{~m}_{\mathrm{h}}$ & $\mathrm{mm}$ & 2.021 & 2.076 & 2.164 & 2.283 & 2.427 & 2.773 & 2.969 & 3.177 & 3.394 & 3.851 \\
\hline \multirow{4}{*}{$8^{\circ}$} & $\begin{array}{l}\mathrm{m}_{\alpha} \text { infl } \\
\text { uence }\end{array}$ & \multirow{3}{*}{$\mathrm{mm}^{2}$} & 0.018 & 0.074 & 0.166 & 0.295 & 0.461 & 0.904 & 1.180 & 1.494 & 1.844 & 2.655 \\
\hline & $\begin{array}{l}\mathrm{m}_{\mathrm{s}} \text { infl } \\
\text { uence }\end{array}$ & & 0.012 & 0.014 & 0.016 & 0.019 & 0.022 & 0.028 & 0.031 & 0.035 & 0.039 & 0.047 \\
\hline & $\begin{array}{c}\mathrm{m}_{\text {highinfl }} \\
\text { uence }\end{array}$ & & 1.000 & 1.000 & 1.000 & 1.000 & 1.000 & 1.000 & 1.000 & 1.000 & 1.000 & 1.000 \\
\hline & $2 m_{h}$ & $\mathrm{~mm}$ & 2.030 & 2.086 & 2.174 & 2.293 & 2.436 & 2.780 & 2.974 & 3.181 & 3.396 & 3.848 \\
\hline \multirow{4}{*}{$15^{\circ}$} & $\begin{array}{l}\mathrm{m}_{\alpha} \text { infl } \\
\text { uence }\end{array}$ & \multirow{3}{*}{$\mathrm{mm}^{2}$} & 0.018 & 0.070 & 0.158 & 0.281 & 0.439 & 0.860 & 1.123 & 1.421 & 1.755 & 2.527 \\
\hline & $\begin{array}{l}\mathrm{m}_{\mathrm{s}} \text { infl } \\
\text { uence }\end{array}$ & & 0.040 & 0.048 & 0.057 & 0.066 & 0.075 & 0.097 & 0.108 & 0.121 & 0.134 & 0.162 \\
\hline & $\begin{array}{c}\mathrm{m}_{\text {highinfl }} \\
\text { uence }\end{array}$ & & 1.000 & 1.000 & 1.000 & 1.000 & 1.000 & 1.000 & 1.000 & 1.000 & 1.000 & 1.000 \\
\hline & $2 \mathrm{~m}_{\mathrm{h}}$ & $\mathrm{mm}$ & 2.057 & 2.115 & 2.205 & 2.321 & 2.461 & 2.798 & 2.987 & 3.189 & 3.399 & 3.841 \\
\hline \multirow{3}{*}{$30^{\circ}$} & $\begin{array}{l}\mathrm{m}_{\alpha} \text { infl } \\
\text { uence }\end{array}$ & \multirow{3}{*}{$\mathrm{mm}^{2}$} & 0.014 & 0.056 & 0.127 & 0.226 & 0.353 & 0.691 & 0.903 & 1.143 & 1.411 & 2.031 \\
\hline & $\begin{array}{l}\mathrm{m}_{\mathrm{s}} \text { infl } \\
\text { uence }\end{array}$ & & 0.151 & 0.180 & 0.211 & 0.245 & 0.281 & 0.361 & 0.405 & 0.451 & 0.500 & 0.604 \\
\hline & $\begin{array}{l}\mathrm{m}_{\text {highinfl }} \\
\text { uence }\end{array}$ & & 1.000 & 1.000 & 1.000 & 1.000 & 1.000 & 1.000 & 1.000 & 1.000 & 1.000 & 1.000 \\
\hline
\end{tabular}

Table 1 Comparison table of the error limit of the opposite observation and the second-order retesting tolerance. known that there are mainly the following aspects that affect the accuracy of the trigonometric elevation measurement:

\subsection{Effect of side length measurement error $\mathrm{m}_{\mathrm{s}}$ on height difference}

$=\frac{1}{2}(\sin a)^{2} \times m_{\mathrm{s}}{ }^{2}$, TS60 total station ranging accuracy $\mathrm{m}_{\mathrm{s}}=0.6 \mathrm{~mm}+1 \mathrm{ppm} \times \mathrm{S}$

\subsection{Effect of vertical angle observation error $\mathrm{ma}$ on height difference}

$=\frac{1}{2}(\mathrm{~S} \cos \alpha)^{2} \times\left(\frac{m_{\alpha}}{\rho}\right)^{2}, \quad$ TS60 total station angle measurement accuracy $\mathrm{m}_{\mathrm{a}}= \pm 0.5$ ", two measurement rounds $\mathrm{m}_{\mathrm{a}}= \pm \frac{0.5^{\prime \prime}}{\sqrt{2}}= \pm 0.35^{\prime}$, Table $2 \mathrm{~m}_{\mathrm{a}}$ is taken as \pm 0.4 ".

\subsection{Effect of instrument height and prism height measurement error on height difference}

$=\frac{1}{2} m_{\text {high }}{ }^{2}, \mathrm{~m}_{\mathrm{i}}=\mathrm{m}_{1}= \pm 1 \mathrm{~mm}$, the influence of $\mathrm{m}_{\text {high }}$ on the height difference in Table $2=1 \mathrm{~mm}^{2}$.

\subsection{Estimation of height difference of opposite observation}

Take $2 m_{h}$ as the error limit of height measurement, and compare it with the re-measurement limit of secondorder measurement. The calculation results are shown in Table 1. 


\begin{tabular}{|c|c|c|c|c|c|c|c|c|c|c|c|c|}
\hline & $2 m_{h}$ & $\mathrm{~mm}$ & 2.159 & 2.224 & 2.313 & 2.426 & 2.557 & 2.865 & 3.038 & 3.221 & 3.412 & 3.813 \\
\hline \multirow{4}{*}{$50^{\circ}$} & $\begin{array}{c}\mathrm{m}_{\alpha} \text { infl } \\
\text { uence }\end{array}$ & \multirow{3}{*}{$\mathrm{mm}^{2}$} & 0.008 & 0.031 & 0.070 & 0.124 & 0.194 & 0.381 & 0.498 & 0.630 & 0.778 & 1.120 \\
\hline & $\begin{array}{l}\mathrm{m}_{\mathrm{s}} \text { infl } \\
\text { uence }\end{array}$ & & 0.355 & 0.422 & 0.495 & 0.575 & 0.660 & 0.847 & 0.950 & 1.058 & 1.173 & 1.419 \\
\hline & $\begin{array}{c}\mathrm{m}_{\text {higinfinfl }} \\
\text { uence }\end{array}$ & & 1.000 & 1.000 & 1.000 & 1.000 & 1.000 & 1.000 & 1.000 & 1.000 & 1.000 & 1.000 \\
\hline & $2 m_{h}$ & $\mathrm{~mm}$ & 2.335 & 2.411 & 2.502 & 2.607 & 2.723 & 2.985 & 3.129 & 3.279 & 3.436 & 3.762 \\
\hline \multicolumn{2}{|c|}{$\begin{array}{c}\text { Second orderlevel } \\
\text { retesting tolerance } 6 \sqrt{\mathrm{L}}\end{array}$} & $\mathrm{mm}$ & 1.897 & 2.683 & 3.286 & 3.795 & 4.243 & 5.020 & 5.367 & 5.692 & 6.000 & 6.573 \\
\hline
\end{tabular}

As can be seen from Table 1:

(1) $\mathrm{S}=200 \sim 1200 \mathrm{~m}$, the second-order retesting tolerance does not exceed the limit.

(2) The effect of vertical angle observation error on the height difference is much greater than the other two. Therefore, the vertical angle observation error is the main factor affecting the trigonometric height difference. The ATR automatic collimation function of the TS60 total station is used to avoid artificial angular error observation.

(3) The measurement error of the instrument height and the prism height also has a greater impact on the height difference, and measures should be taken to avoid error in measuring instrument height and prism height.

(4) Considering the automatic aiming accuracy limitation of the total station, the side length should not be too long, it should generally be $\leq 1 \mathrm{~km}$, and the number of rounds should be appropriately increased.
(5) Although the vertical angle has little effect on accuracy, the tilting-axis error of the total station is proportional to the vertical angle. Generally, the vertical angle is $\leq 10^{\circ}$, and it is controlled within $20^{\circ}$ in special cases.

\section{Application examples}

\subsection{Project Overview}

In December 2017, our institute was commissioned by Xanga Municipal Construction Group Co., Ltd. to use the Leica TS60 total station to measure the precise trigonometric elevation replacing the second-order level for the elevation control measurement of the tunnel $12^{\#}$ in Qi xi an to Li shi Expressway, Shanxi. The tunnel length is about $10 \mathrm{~km}[2]$.

\subsection{Trigonometric elevation control network diagram}

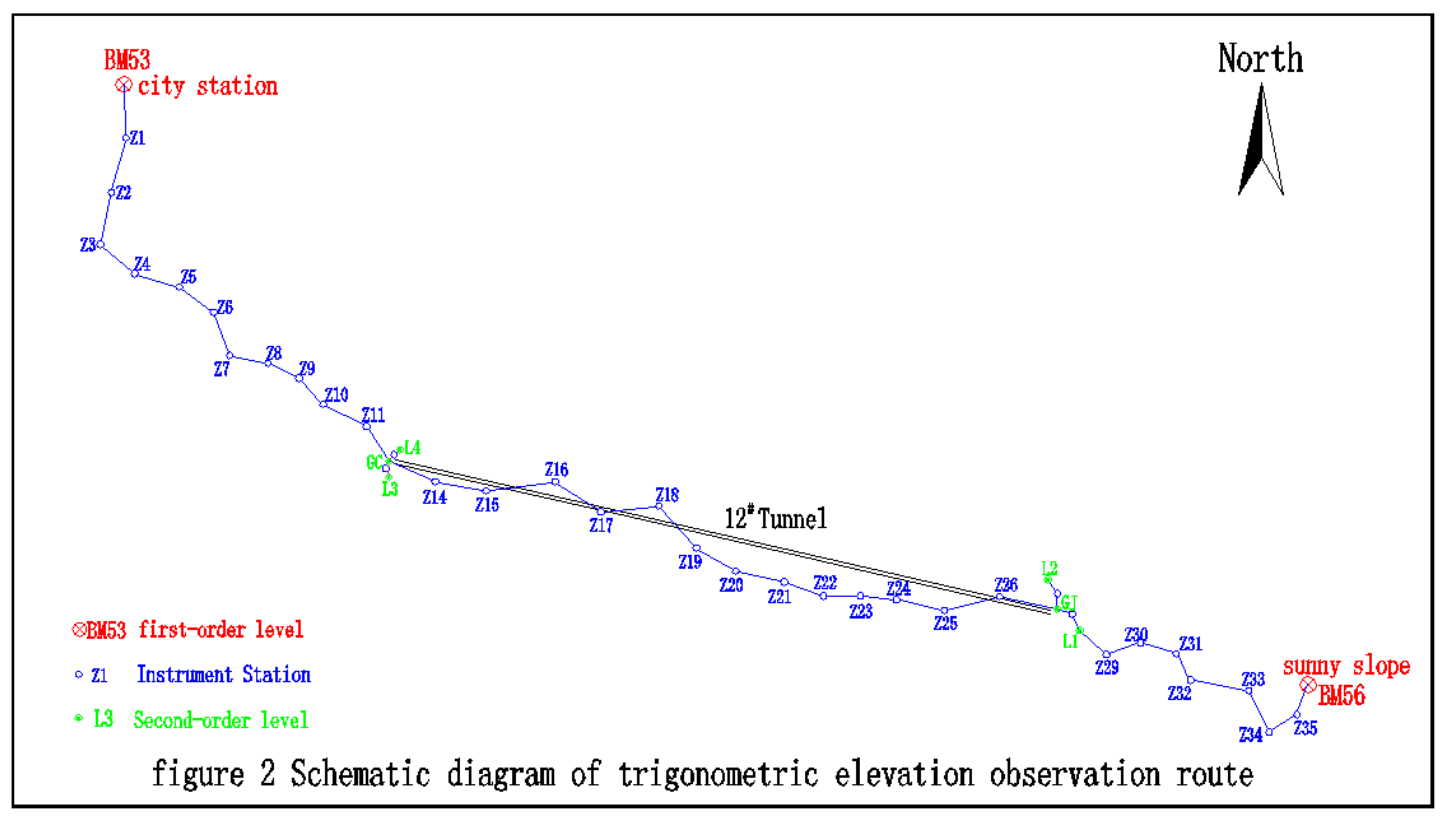

\subsection{Precise trigonometric elevation measurement method}

(1) Non-destructive modification of two TS60 total stations with automatic collimation function. Install two collimation prisms on the handle of the total station for automatic collimation facing observation, which can basically eliminate or greatly weaken the spherical aberration impact.

(2) Determination of high and low prism constants: Set up a TS60 total station on a flat ground, and place high and low prisms about $20 \mathrm{~m}$ away. Measure the height difference between low and high prisms multiple times. The difference between the heights is the high and low prism constants. The high and low prism constants are used to check the station height difference.

(3) After one side observation is completed, the next side observation is performed. At this time, special attention should be paid to the fact that the front station does not move, and it is the back station of the next side. The original instrument is moved to the front, and the next station is the front station. The opposite side of the 
measurement section is an even number of sides, and each measurement section performs back and forth double prism observations in the order of back low, front low, front high, and back high. At the same time, the height is set at the starting and ending level of the measurement section. The same prism rod does not change, which can completely avoid error in measuring instrument height and prism height[3].

(4) Generally $0.2 \mathrm{~km} \leq \mathrm{S} \leq 1 \mathrm{~km}$, distance and vertical angle $\mathrm{S}=0.2 \sim 0.5 \mathrm{~km}, 4$ rounds are measured; 6 rounds are measured at $0.5 \sim 0.8 \mathrm{~km} ; 8$ rounds are measured at

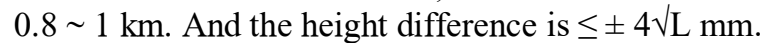

\subsection{Precision trigonometric elevation measurement accuracy}

The trigonometric elevation control survey of the $12^{\#}$ tunnel from Qixian to Lishi Expressway takes the firstlevel point BM53 as the starting point and finally attaches to the first-level point BM56 via the trigonometric elevation route. See Table 2 for measurement accuracy.

Table 2 Precision trigonometric elevation accuracy table

\begin{tabular}{|c|c|c|c|c|c|c|}
\hline Section name & Distance (m) & $\begin{array}{c}\text { Backward } \\
\text { measurement } \\
\text { height } \\
\text { difference }(\mathrm{m})\end{array}$ & $\begin{array}{c}\text { Backward } \\
\text { measurement } \\
\text { height } \\
\text { difference }(\mathrm{m})\end{array}$ & $\begin{array}{l}\text { Average height } \\
\text { difference }(\mathrm{m})\end{array}$ & $\begin{array}{l}\text { Round trip } \\
\text { measurement } \\
\text { difference } \\
(\mathrm{mm})\end{array}$ & $\begin{array}{l}\text { Round trip } \\
\text { measurement } \\
\text { limit difference } \\
(\mathrm{mm})\end{array}$ \\
\hline BM53-GC & 7966.317 & 117.8854 & -117.8769 & 117.8812 & 8.5 & 11.3 \\
\hline GC-L3 & 233.736 & -11.6352 & 11.6340 & -11.6346 & -1.2 & 1.9 \\
\hline GC-L4 & 220.311 & -9.2075 & 9.2086 & -9.20805 & 1.1 & 1.9 \\
\hline GC-GJ & 10502.738 & 112.2907 & -112.2800 & 112.2854 & 10.7 & 13.0 \\
\hline GJ-L2 & 361.229 & -4.1877 & 4.1856 & -4.18665 & -2.1 & 2.4 \\
\hline GJ-L1 & 388.421 & 8.2665 & -8.2646 & 8.26555 & 1.9 & 2.5 \\
\hline L1-BM56 & 4573.529 & 13.4451 & -13.4367 & 13.4409 & 8.4 & 8.6 \\
\hline total & 24246.2810 & 226.8573 & -226.8300 & 226.8436 & & \\
\hline Accuracy & \multicolumn{6}{|c|}{$\triangle \mathrm{h}=\mathrm{h}-\left(\mathrm{H}_{56}-\mathrm{H}_{53}\right)=226.8436 \mathrm{~m}-226.8312 \mathrm{~m}=12.4 \mathrm{~mm}<\triangle \mathrm{h}_{\text {limit }}=4 \sqrt{\mathrm{L}}=19.7 \mathrm{~mm}$} \\
\hline
\end{tabular}

It can be seen from Table 2 that the round-trip observation of each level of the route is poor, and all are less than the round-trip measurement limit. The line closure difference is $12.4 \mathrm{~mm}$, which is less than the limit requirement of $19.7 \mathrm{~mm}$. According to the statistical calculation of the difference, the total mid-range error per kilometer is measured. It is $1.3 \mathrm{~mm}$, which satisfies the accuracy of second-level measurement. The construction unit uses the Leica DNA03 leveler to set up a second-level test, which meets the requirements.

\section{Conclusion}

Qixian to Lishi Expressway $12^{\#}$ tunnel penetrating elevation control, using TS60 total station with automatic collimation function for opposite precision trigonometric elevation measurement, which can reduce or eliminate measurement errors from three aspects: people, instruments and observation environment. The results are reliable, so it is feasible under certain conditions to replace the second-order leveling with a precise trigonometric elevation method.

\section{Author}

Zhang Hong feng male Lin fen, Shanxi people 1973.11.28 senior professional bachelor's degree: engineering survey, aerial survey and remote sensing.

\section{References}

1. Kong Xiangming, Control Surveying [M]. Wuhan: Wuhan University Press, 2011

2. Chen Longfei, JinQikun, Engineering Surveying [M]. Shanghai: Tongji University Press, 1990

3. Discipline group of survey adjustment, School of Surveying and Mapping, Wuhan University, error theory and survey adjustment [M]. Wuhan: Wuhan University Press, 2005 